\title{
O Impacto do Ensino dos Conceitos de Mecânica Quântica na Graduação em Química
}

Aquímica quântica pode ser considerada uma das maiores realizações da ciência moderna podendo ser equiparada aos grandes desenvolvimentos científicos do século XX, como a descoberta do código genético e a relatividade geral. A química quântica é capaz de explicar fenômenos de interesses da química fundamental, como bandas espectrais dos compostos químicos, assim como, fenômenos de interesse tecnológicos como supercondutividade e superfluidez. Seus conceitos iniciais datam de 1900, levando a uma revolução no modo clássico de se pensar e de fazer química. Os primeiros argumentos teóricos e o aparato matemático da mecânica quântica foram majoritariamente desenvolvido por físicos (Max Planck, Niels Bohr, Louis de Broglie, Albert Einstein e Erwin Schrödinger) entretanto, os novos conceitos não-convencionais propostos nesta área foram rapidamente assimilados pelos químicos (Linus Pauling, Robert Sanderson Mulliken, Erich Hückel e Henry Eyring) promovendo grandes realizações para o entendimento do mundo molecular. Desta a forma, pode-se indagar: Quais conceitos de mecânica quântica são fundamentais para a evolução do pensamento moderno em química para um graduando? A estrutura da mecânica quântica é bastante ampla e complexa, entretanto, pode-se destacar dois conceitos que fazem parte da essência da química moderna: i) a quantização de propriedades microscópicas, isto é, a discretização de parâmetros moleculares, característica inerente ao aprisionamento de partículas mediante campos de potencial moleculares; e o ii) caráter probabilístico, no qual limita a possibilidade de determinar com exatidão certas propriedades das partículas simultaneamente, característica inerente ao comportamento ondulatório da matéria. Estes dois conceitos promoveram uma revolução na compreensão do mundo atômico, fornecendo explicações robustas na forma como os átomos se estabilizam e como estes interagem durante um processo reativo.

Dentro deste contexto, vale indagar: Como estes conceitos e tantos outros inerentes a mecânica quântica podem ser correlacionados com as disciplinas básicas de graduação em química? Nos livros clássicos de graduação em química, estes conceitos estão permeados nos vários ramos disciplinares: i) Química Geral - estabilidade da estrutura atômica mediante a ideia de quantização energética e o caráter probabilístico dos elétrons levando a construção de orbitais, a periodicidade da tabela periódica proposta por Moseley através da correlação de orbitais atômicos com bandas espectrais, a formulação de teorias de ligação química (Ligação e Valência e Orbital Molecular) a partir da combinação matemática de orbitais atômicos; ii) Química Orgânica e Inorgânica - compressão dos canais reativos de uma reação química a partir do vínculo da sobreposição de orbitais moleculares e o estado energético de compostos moleculares, definido a partir da superfície de energia potencial, com consequente identificação de estados de transição; iii) Termodinâmica e Cinética Química - Correlação da espontaneidade e da velocidade de processos químicos a partir de propriedades energéticas ( Energia Livre de Gibbs e Energia de Ativação) obtidas através da superfície de energia potencial. Também é 
possível explicar os efeitos isotópicos e alta reatividade a baixas temperaturas, utilizando os conceitos quânticos de tunelamento (penetração de uma barreira energética por uma partícula mesmo possuindo energia insuficiente para sobrepô-la) e de energia de ponto-zero (consequência imediata do princípio da incerteza de Heisenberg devido o movimento vibracional de moléculas) e; iv) Análise Instrumental, que permite a análise e caracterização de sistemas moleculares utilizando técnicas de Infra-vermelho, UV-Visível, Absorção-Emissão atômicas e Ressonância Magnética Nuclear. A compreensão dessas técnicas só são possíveis a partir do conceito de quantização de parâmetros energéticos a nível atômico, levando a percepção de bandas espectrais a nível macroscópico.

Um entendimento abrangente da mecânica quântica, carece de um pesado aparato matemático, então surge o seguinte questionamento: Para o nível de graduação em química qual deve ser o balanço entre o aprofundamento de formulações matemáticas e a inserção de conceitos de mecânica quântica? Este questionamento torna-se pertinente, uma vez que muitos graduandos ainda tem uma visão pessimista em relação a disciplina de química quântica, tomando a disciplina como um amontoado de equações diferenciais com resoluções de alta complexidade e vendo a mesma como inútil e/ou apenas como um elemento que vem a dificultar a obtenção de seu diploma. As formulações matemáticas utilizadas, mesmo sendo importantes, muitas vezes pode se tornar tediosa para o aprendizado de química quântica. Tomando-se como exemplo o caso da solução do oscilador harmônico, tópico essencial na disciplina de química quântica que permite a compressão da técnica espectroscópica no Infra-vermelho, carece de certo manuseio e artifícios matemáticos de séries de potência para a solução de equações diferenciais (método de Frobenius). As etapas da solução e ensino deste problema é demorada e complexa em um primeiro momento, entretanto necessária, pois apresenta conceitos matemáticos (polinômios de Hermite) que tornará a solução posterior do átomo de hidrogênio mais intuitiva e rápida. O método de Frobenius será aplicável novamente (polinômios de Laguerre e Legendre) economizando tempo que pode ser capitalizado para o aprofundamento do conceito de orbitais atômicos e formalização de esquemas de distribuição eletrônica em sistemas polietrônicos. Desse ponto de vista, a nível de graduação o aparato matemático pode ser tomado como ferramenta e não como força motriz para o aprendizado de química quântica.

Uma vez que estes conceitos são transversais nas várias disciplinas da graduação em química, quais são as consequências de um formando (licenciado, bacharel e tecnológico) no mercado de trabalho que não possui os conceitos de mecânica quântica? É difícil imaginar que uma ciência que está bem fundamenta a mais de um século pode ser vista como negligenciável para a formação de um químico. Parafrasear um dos grandes pensadores da mecânica quântica, Paul Dirac, torna esta constatação ainda mais inquietante: "...grande parte da física e toda a química pode ser completamente conhecida... a partir de métodos práticos de mecânica quântica...". Considerando que a mecânica quântica é a alma da química moderna, é certo que ao lançar químicos no mercado de trabalho que não possuam pensamento quântico, cria um efeito danoso ao disponibilizar educadores que criarão um círculo de difusão de conceitos clássicos e ultrapassados em química, e também ao limitar o poder de solução dos problemas enfrentados no mercado de trabalho do químico tecnológico. O químico sem fundamentos quânticos acaba fomentando o empirismo químico de August Conte que atestava: "Toda tentativa de empregar métodos matemáticos no estudo de questões químicas deve ser considerada profundamente irracional e contrária ao espírito químico ... Se a análise matemática já tivesse um lugar proeminente na química uma aberração, que é felizmente quase impossível - seria uma degeneração rápida e generalizada dessa ciência." Pode-se supor que um educador em química do ensino básico que tivesse seu conhecimento químico limitado a conceitos clássicos ficaria facilmente acuado em responder questões mais aprimoradas de discentes com intelecto mais aguçados em ciências naturais. Ou ainda, não seria possível esperar respostas convincentes de um tecnólogo que estivesse vinculado ao setor produtivo a indagações de órgãos de controle quando produtos químicos 
manufaturados (medicamentos, alimentos, cosméticos, entre outros) apresentassem eficácia discrepante daquilo que é exigido por lei.

Certo de que a mecânica quântica é um tópico de extrema importância para a compreensão da química e da necessidade de se avançar em mecanismos de ensino da mesma a nível de graduação, deixamos a seguinte provocação. No papel de professores e pesquisadores, qual a nossa parcela de responsabilidade e de contentamento ao fomentar a formação de um químico com cultura química a nível dos modelos atômicos de: i) Dalton, limitado a compressão de cálculos estequiométricos; ii) Thomson, com um mero avanço em problemas químicos que envolvem eletricidade (eletroquímica); iii) Rutherford e Borh, com alguns avanços nos conceitos da velha mecânica quântica ficando limitados a átomos hidrogenóides ou iv) a visão de Schrödinger e Born, o qual incorpora todos os modelos prévios e pavimenta o avanço no estado da arte em química?

Devido aos esforços dos organizadores e como estímulo para os participantes, estas notas foram escritas para compor a coleção de artigos apresentados na ocasião do 'XXXVI Encontro Nacional dos Estudantes de Química' em Goiânia- GO em janeiro de 2018. Gostaria de agradecer as frutíferas discussões com os professores Kleber Mundim (UnB), Freddy Guimarães (UFG), Ademir Camargo (UEG) e Nayara Dantas (SENAI).

\section{Valter H. Carvalho-Silva ${ }^{*}$ \& Lílian T. F. M. Camargo ${ }^{2}$}

${ }^{1}$ Grupo de Química Teórica e Estrutural de Anápolis, Campus de Ciências Exatas e Tecnológicas, Universidade Estadual de Goiás, Caixa Postal 459, 75001-970, Anápolis, Goiás, Brasil

${ }^{2}$ Instituto Federal de Educação, Ciência e Tecnologia de Goiás - Campus Anápolis, CEP 75131-457, Anápolis-GO, Brasil.

*E-mail: fatioleg@gmail.com 